\title{
Optical sensor for flow measurement in microstructures
}

\author{
J. Zosel ${ }^{1}$, D. Petrak ${ }^{2}$, H. Rauh ${ }^{2}$, U. Guth ${ }^{1}$ \\ ${ }^{1}$ Meinsberg Kurt-Schwabe Research Institute, ${ }^{2}$ Chemnitz University of Technology \\ ${ }^{1}$ Kurt-Schwabe-Straße 4, D-04720 Ziegra-Knobelsdorf, ${ }^{2}$ D-09126 Chemnitz, Germany
}

\section{Outline of the problem}

The galvanic production of electronic and micro mechanical components is accompanied by continuous miniaturisation of structures and therefore needs to be improved with respect to the exchange rate of electrolytes and cleaning fluids in the micro structures [1]. Numerous conditions in modern devices for continuous galvanic plating of microstructures are opposed to the application of electrical, thermal and electrochemical sensors as well as to classical optical methods like micro-PIV or micro-LDA for flow measurements in the electrolyte [2]. Electrochemical flow sensors were used for this purpose successfully [3], but they require time consuming and frequent calibration and are not easy to use in those devices.

\section{Innovation of solution}

To provide a sensor and a measuring method for investigation and monitoring of electrolyte flow in galvanic baths for the production of micro structures, the principle of flow measurement with a fibre optical spatial filter [4] was adapted to a micro capillary and tested in free impinging jet flows.

\section{Technical realisation}

\subsection{Measuring principle}

The basic principle of the flow meter sensor for microstructures is given in Fig. 1. The micro structure was made from a glass capillary (Schott AG) with inner diameter $d_{i}=150 \mu \mathrm{m}$ and length $I=2 \mathrm{~mm}$. A fibre optical differential spatial filter was positioned parallel to the capillary axis and illuminated from the opposite side by a parallel beam from an LED-system. Tracer particles in the flow throw shadows with the same size on the fibres and the result is a sinusoidal output of the differential amplification from the output signals of the two photo diodes. The particle velocity $u_{p}$ results from the product of periodic time $T$ and filter constant $g$. Using tracer particles with size of few micrometers and with a density near to the fluid density, the fluid velocity $u$ is quite equal to the tracer particle velocity $u_{p}$. The flow of a Newtonian fluid requires the so-called entrance length $l_{e}$ for the full development of the parabolic velocity profile, which can be calculated by Equation 1, developed from numerical investigations of Durst et al. [5].

$$
\frac{l_{e}}{d_{i}}=\left[(0.619)^{1.6}+(0.0567 \cdot \operatorname{Re})^{1.6}\right]^{111.6}
$$

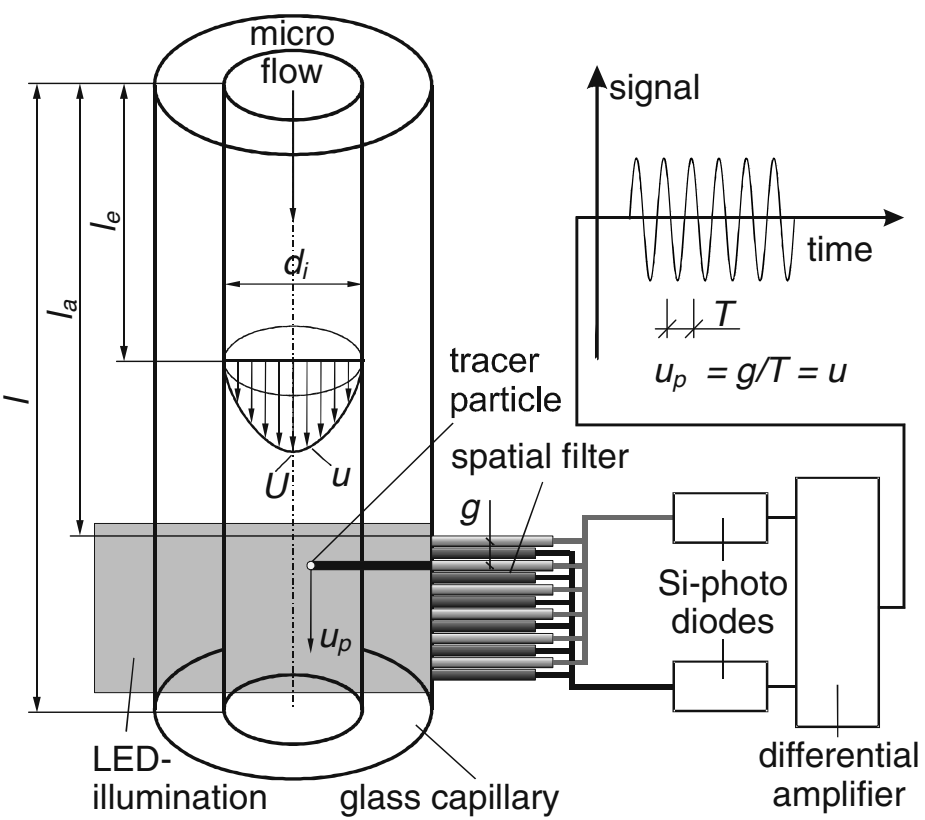

The flow rate $q_{v}$ can be calculated from the measured velocity $U$ of the fastest particles at the capillary axis by Equation 2 .

$$
q_{V}=\frac{\pi d_{i}^{2}}{4} \cdot \frac{U}{2}
$$

Fig. 1: Principle of the optical flow rate measurement in micro capillary using differential spatial filter, $l_{e}$ entrance length, required for full development of parabolic velocity profile, $l_{a}$ available entrance length, $u$ flow velocity, $U$ maximum flow velocity at the capillary axis, $u_{p}$ tracer particle velocity, $g$ interval between two adjacent fibres of one bundle, $T$ periodic time 


\subsection{Sensor configuration}

The newly developed sensor with the dimensions $100 \times 60 \times 5 \mathrm{~mm}^{3}$ is illustrated in Fig. 2 as a longitudinal section through the sensor centre together with the connections to the light source and signal conversion.

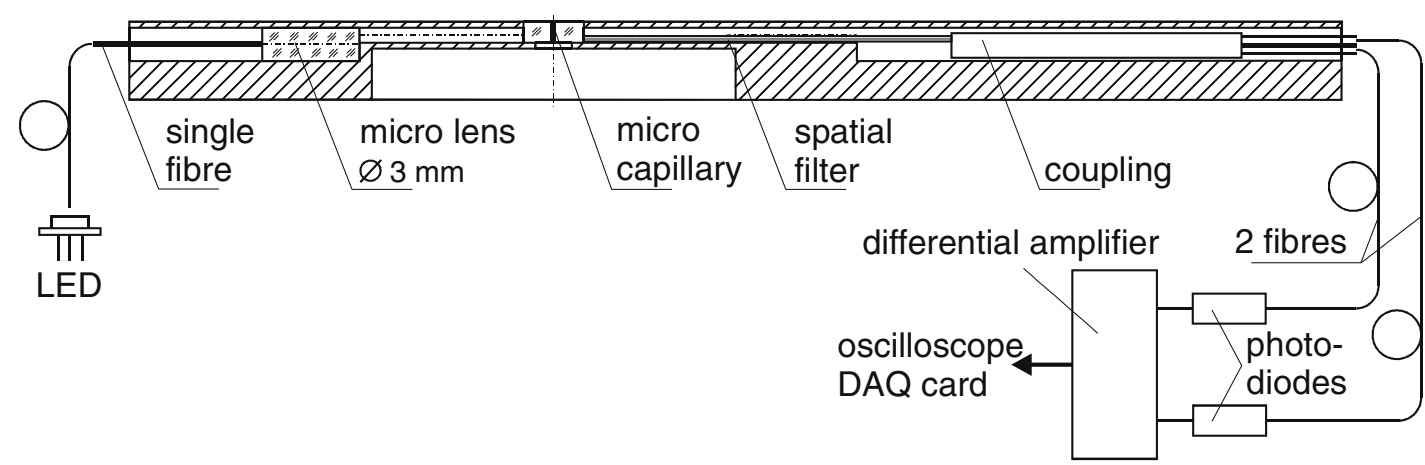

Fig. 2: Longitudinal section of the sensor with fibre optical connections

The body is composed of a thin upper plate and a lower plate for the integration of the optical elements. The outer diameter of the capillary amounts to $5 \mathrm{~mm}$. The light of a LED, $(\lambda=850 \mathrm{~nm}$, power $1 \mathrm{~mW})$ is fed by a standard optical fibre to a micro lens for generation of a parallel light beam. The double spatial filter (Parsum $\mathrm{GmbH}$, Chemnitz) is made by $2 \times 6$ step index fibres with core diameter $64 \mu \mathrm{m}$, numerical aperture 0.2, interval $g=174 \mu \mathrm{m}$ and total length $0.9 \mathrm{~mm}$. It is fixed at the downstream side of the capillary to maximise the available entrance length to $l_{a}=1 \mathrm{~mm}$. All sensor parts are assembled and sealed by silicon elastomer. After coupling two standard optical fibres are connected with two photodiodes. The two signals are fed to a differential amplifier for removing the pedestal component, and the resulting signal was analysed by Fast Fourier Transform (FFT). The tracer particle signals are evaluated by determining signal periods, deviation of periods, uncertainty of the frequency maximum and signal-to-noise ratio. Software development was completely based on the graphical programming language LabVIEW ${ }^{\mathrm{TM}}$, while a DAQ scope card 5102 from National Instruments ${ }^{\mathrm{TM}}$ with 12 bits input resolution and $5 \mathrm{MHz}$ sampling rate was used for data acquisition.

\subsection{Setups for free impinging jets}

The experimental setup for laboratory tests is schematically shown in Fig. 3. A free impinging laminar or turbulent axisymmetric water jet is generated by circular glass nozzles with different diameters $D_{0}$. Providing the flow by means of a progressing cavity pump (Netzsch $\mathrm{GmbH}$ ) the jet always has a pulsation

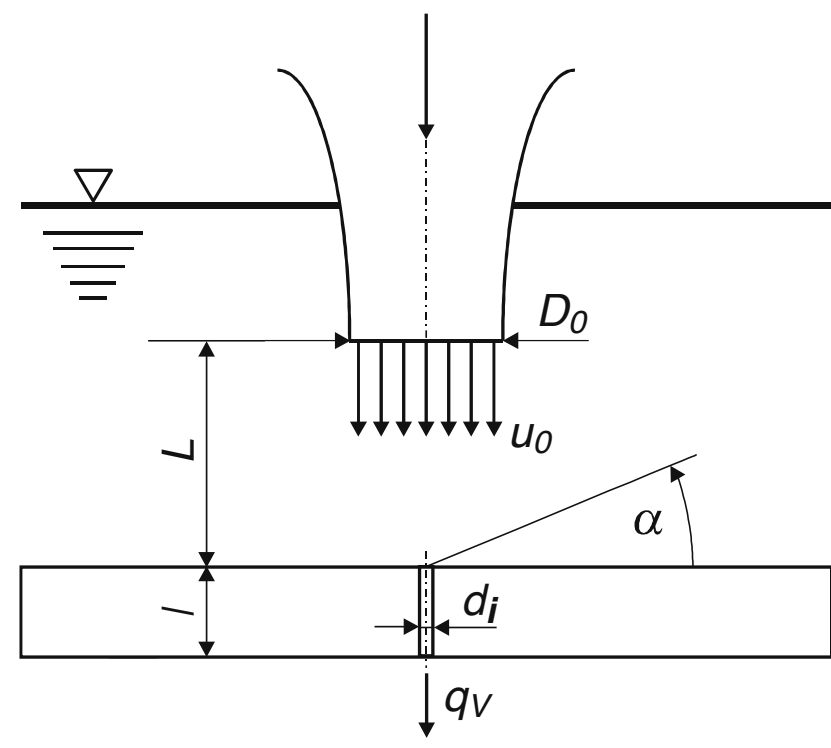
free and uniform velocity profile $u=u_{0}=$ const at nozzle exit. The sensor is arranged at distance $L$ from the nozzle exit and could be adjusted at different angle positions $\alpha$ to the jet axis. All experiments were carried out in a rectangular vessel with $26 \times 10 \times 10 \mathrm{~cm}^{3}$ by fixing the sensor horizontally in a position where the axis of the jet crosses the capillary entrance center. The micro flow $q_{v}$ through the capillary was measured in dependence on the jet velocity $u_{0}$, the distance $L$ from the nozzle exit and the angle of inclination $\alpha$. Distilled water was used as the fluid, which contains hollow glass beads as tracer particles with diameters $d_{p}=9 \ldots 13 \mu \mathrm{m}$ and density $\rho=1100 \mathrm{~kg} / \mathrm{m}^{3}$.

Fig. 3: Schematic view of the arrangement for sensor tests in free impinging circular wall jets

For testing the sensor at conditions similar to those of galvanic lines for horizontal plating of printed circuit boards, it was integrated in a technical setup representing a section of a plating line with the length $1 \mathrm{~m}$. 
This setup, which is described in detail elsewhere [6], was equipped with an array of slit nozzles as

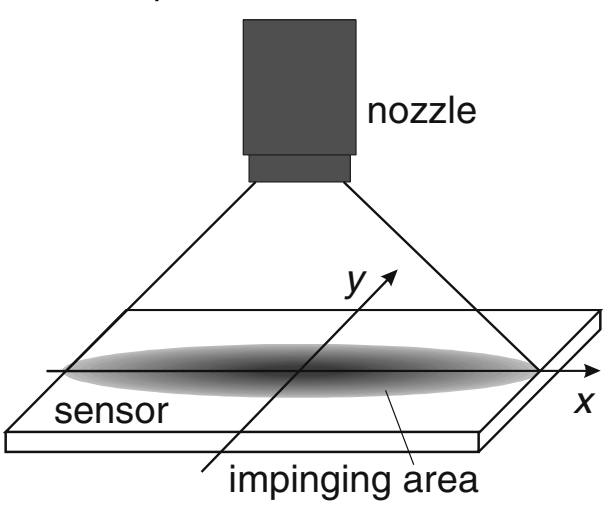
shown in Fig. 4 and filled with distilled water containing also the hollow glass beads as tracer particles. To characterise the sensor, it was mounted like a printed cirquit board to be plated with the distance $12 \mathrm{~mm}$ between nozzle outlet and capillary entrance. All experiments were carried out by varying nozzle flow rate between 1.5 and $3.4 \mathrm{I} \cdot \mathrm{min}^{-1}$. Capillary flows were measured at different equidistant horizontal sensor positions with $\Delta x=3 \mathrm{~mm}$ and $\Delta y=1 \mathrm{~mm}$ (Fig. 4).

Fig. 4: Sensor adjustment under a slit nozzle, integrated in an anode segment of a plating line section.

\section{$4 \quad$ Results}

\subsection{Sensor calibration}

To characterise the sensor performance water with glass beads was pressed through the capillary at predetermined flow rates between $0.01 \ldots 200 \mathrm{ml} \cdot \mathrm{h}^{-1}$ by a syringe pump (B. Braun Melsungen AG) with the accuracy $2.5 \%$. A characteristic signal of a single tracer particle with a dominant frequency is shown in Fig. 5. The curve of the sensor calibration given in Fig. 6 deviates increasingly from the dashed straight line at $q_{V}>50 \mathrm{ml} \cdot \mathrm{h}^{-1}$. This result shows that the available entrance length $l_{a}$ of the capillary enables the formation of a fully developed laminar profile up to flow rates of $50 \mathrm{ml} \cdot \mathrm{h}^{-1}$. At higher flow rates the required entrance length $I_{e}$ is longer than $I_{a}$ and, due to the incompletely developed laminar profile, the measured flow rate is lower than the predetermined one. Approximating the curve with the second order polynomial given in Fig. 6 , the complete calibration range can be used to measure flow rates $q_{V \text {,sensor }}$ in the capillary under the influence of a free impinging nozzle jet and to transfer those values into $q_{V}$ values by means of Equation 3.

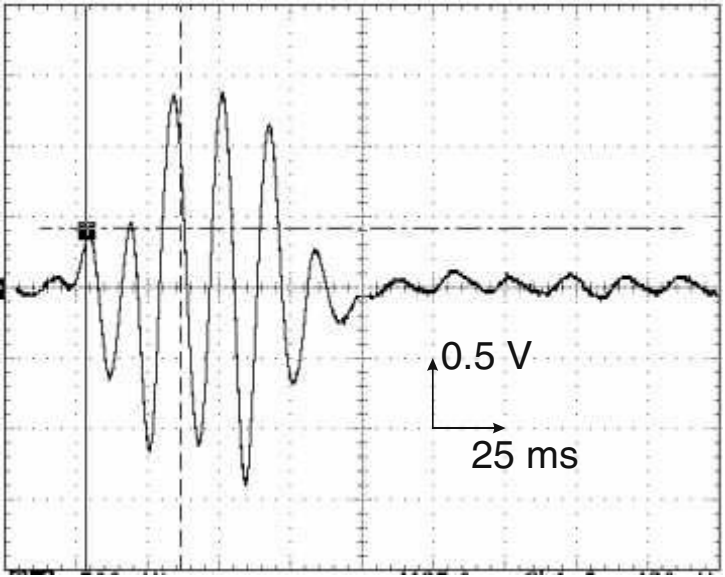

Fig. 5: Oscillogram of a single hollow glass bead passing the spatial filter, $q_{V}=0.5 \mathrm{ml} \cdot \mathrm{h}^{-1}$. $u_{p}=g / T=1.74 \cdot 10^{-4} \mathrm{~m} / 0.016 \mathrm{~s}=0.011 \mathrm{~m} / \mathrm{s}$

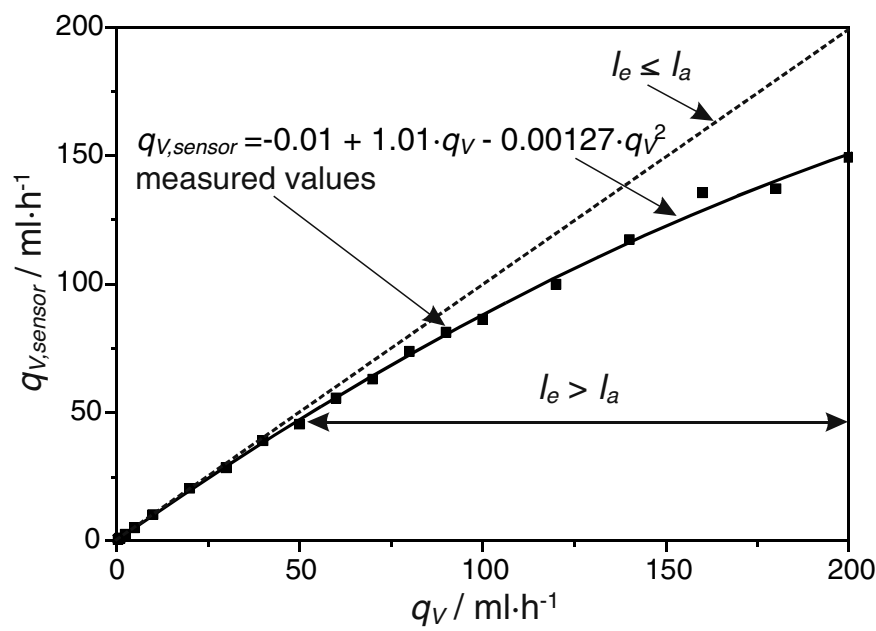

Fig. 6: Calibration curve of the sensor in Fig. 2, $I_{e}$ required entrance length, $l_{a}$ available entrance length, $q_{v}$ flow rate of the predetermined pump flow, $q_{v, \text { sensor }}$ flow rate measured by the sensor

$$
q_{V}=0.38+0.92 \cdot q_{V, \text { sensor }}+0.00254 \cdot q_{V, \text { sensor }}^{2}
$$

The calibration curve in Fig. 6 also confirms the validity of the numerically established Equation 1, which results in $l_{e} \approx 1.0 \mathrm{~mm}$ for $R e=118$ at $q_{V}=50 \mathrm{ml} \cdot \mathrm{h}^{-1}$ and $d_{i}=0.15 \mathrm{~mm}$.

\subsection{Free impinging axisymmetric jet}

Measured flow rates $q_{V}$ for the nozzles with $D_{0}=0.79 \mathrm{~mm}$ and $D_{0}=1.49 \mathrm{~mm}$ are given in Fig. 7 and Fig. 8 in dependence on the nozzle exit velocity $u_{0}$ and impinging angle $\alpha$. Generally, the volume flow through the capillary rises with increasing $u_{0}$ and decreasing impinging angle. This tendency is interrupted between $u_{0}=3 \ldots 4 \mathrm{~m} / \mathrm{s}$ at $R e=2370 \ldots 3160$ for $D_{0}=0.79 \mathrm{~mm}$ and $u_{0}=1 \ldots 2 \mathrm{~m} / \mathrm{s}$ at $R e=1500 \ldots 2970$ for $D_{0}=1.49 \mathrm{~mm}$, respectively, where the jet changes between laminar and turbulent regime. 

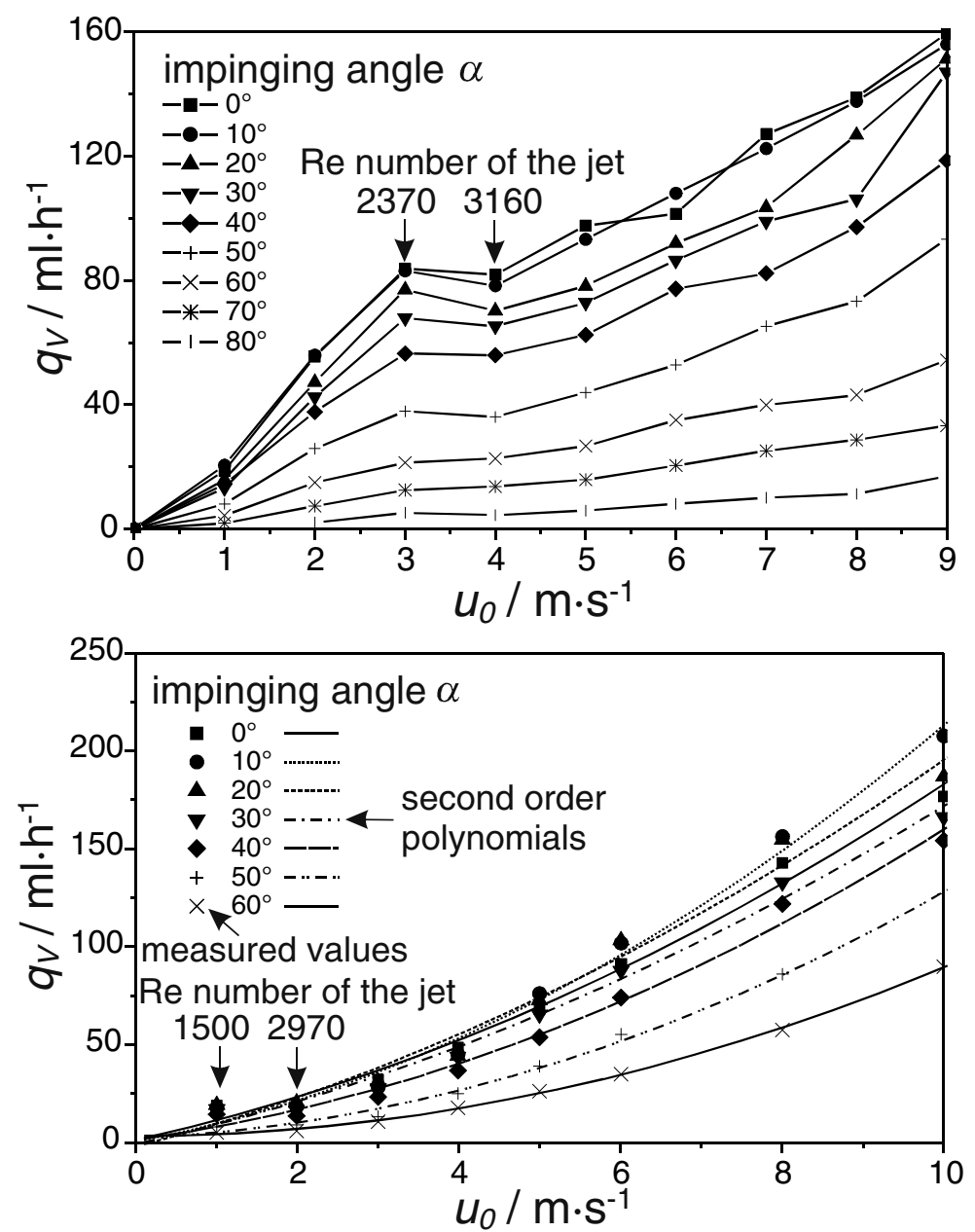

Fig. 7: Flow rate $q_{v}$ in the sensor capillary, measured in the setup according to Fig. 3 under the influence of a free impinging jet at different exit velocities $u_{0}$ and impinging angles $\alpha$, nozzle diameter $D_{0}=0.79 \mathrm{~mm}$, distance $L=10 \mathrm{~mm}$, transition from laminar to turbulent jet between $u_{0}=3 \ldots 4 \mathrm{~m} / \mathrm{s}$
Fig. 8: Flow rate $q_{v}$ according to Fig. 3, nozzle diameter $D_{0}=1.49 \mathrm{~mm}$, distance $L=20 \mathrm{~mm}$, transition from laminar to turbulent jet between $u_{0}=1 \ldots 2 \mathrm{~m} / \mathrm{s}$

Interestingly no significant differences of $q_{V}$ were found between $\alpha=0^{\circ}$ and $10^{\circ}$ in case of the smaller nozzle diameter $D_{0}=0.79 \mathrm{~mm}$, while at $D_{0}=1.49 \mathrm{~mm}$ maximum values were found at $\alpha=10^{\circ}$, which differ significantly from those at $\alpha=0^{\circ}$. The $q_{V}$ values measured at $D_{0}=1.49 \mathrm{~mm}$ can be approximated by second order polynomials.

A comparison between measured and calculated flow rates $q_{V}$ is illustrated in Figs. 9 and 10 . The calculation is based on the known Equation 4 for a laminar flow in a pipe with smooth wall:

$$
q_{V}=\frac{\pi \Delta p}{8 \eta l}\left(\frac{d_{i}}{2}\right)^{4}
$$

where $\Delta p$ is the pressure drop and $\eta$ the dynamic viscosity of the liquid. Inside a laminar jet the pressure drop can be determined by the dynamic pressure $0.5 \rho u_{0}^{2}$. On the experimental conditions of the measurements in Fig. 7 and 8 the core of the turbulent axisymmetric jet is shorter than the distance $L$. According to [7], Equation 5 gives a sufficient approximation of $\Delta p$ outside the core of a turbulent jet:

$$
\Delta p=38.44 \frac{\rho}{2} u_{0}^{2}\left(\frac{D_{0}}{L}\right)^{2}
$$

The curves in Figs. 9 and 10 show, that the measured values agree with the calculated ones for small nozzle velocities in the laminar jet regime. At higher $u_{0}$ values the flow rate converges more and more to the values calculated by Equation 5, while at maximum $u_{0}$ values the measured values are lower than the calculated ones. Therefore it seems to be possible to estimate the flow rate in a through hole also in technical setups if the velocity profile of the nozzle is known. 

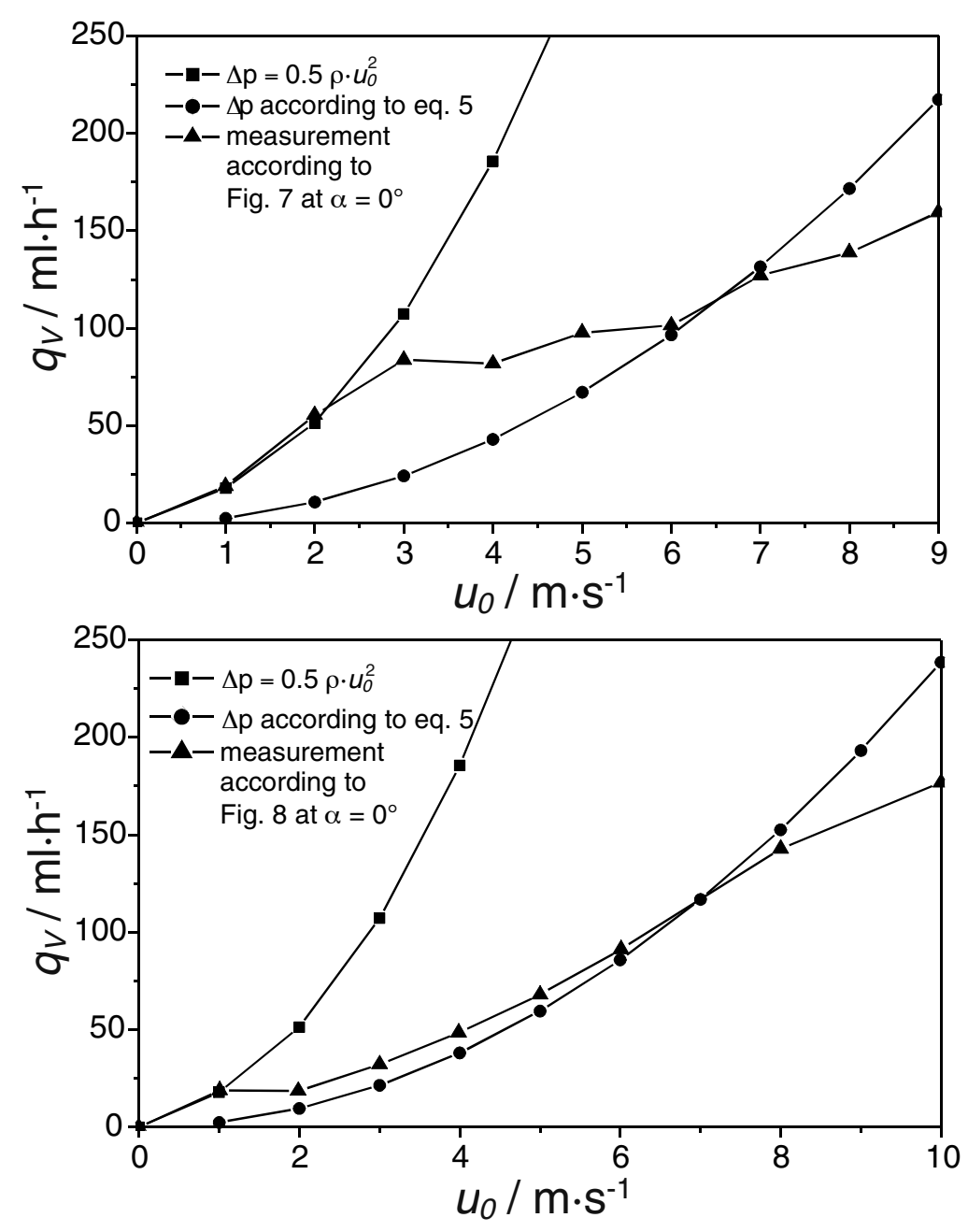

Fig. 9: Comparison between measured and calculated flow rate values $q_{v}$ in the capillary according to Fig. 7 under the influence of a free impinging jet at different exit velocities $u_{0}$, impinging angle $\alpha=0^{\circ}$, other conditions as given in Fig. 7

Fig. 10: Comparison between measured and calculated flow rate values $q_{v}$ in the capillary according to Fig. 8, impinging angle $\alpha=0^{\circ}$, other conditions as given in Fig. 8

\subsection{Sensor behaviour in the galvanic line for horizontal plating}

The flow rates measured in the sensor capillary under the influence of a jet from a slit nozzle according to Fig. 4 are shown as three dimensional curves in Fig. 11 for different nozzle flow rates. The values indicate that the length in $y$-direction with significant capillary flow is relatively short compared to the distance between two consecutive nozzles, often larger than $10 \mathrm{~cm}$ in horizontal plating lines. The 2.3-fold increase of the nozzle flow rate leads to nearly 2 -fold increase of maximum capillary flow. The base length in $x-$ direction of the right cone in Fig. 11 has also a nearly 2-fold value than that of the left cone, while the increase in y-direction is significantly lower than 2-fold (see also Fig. 12).
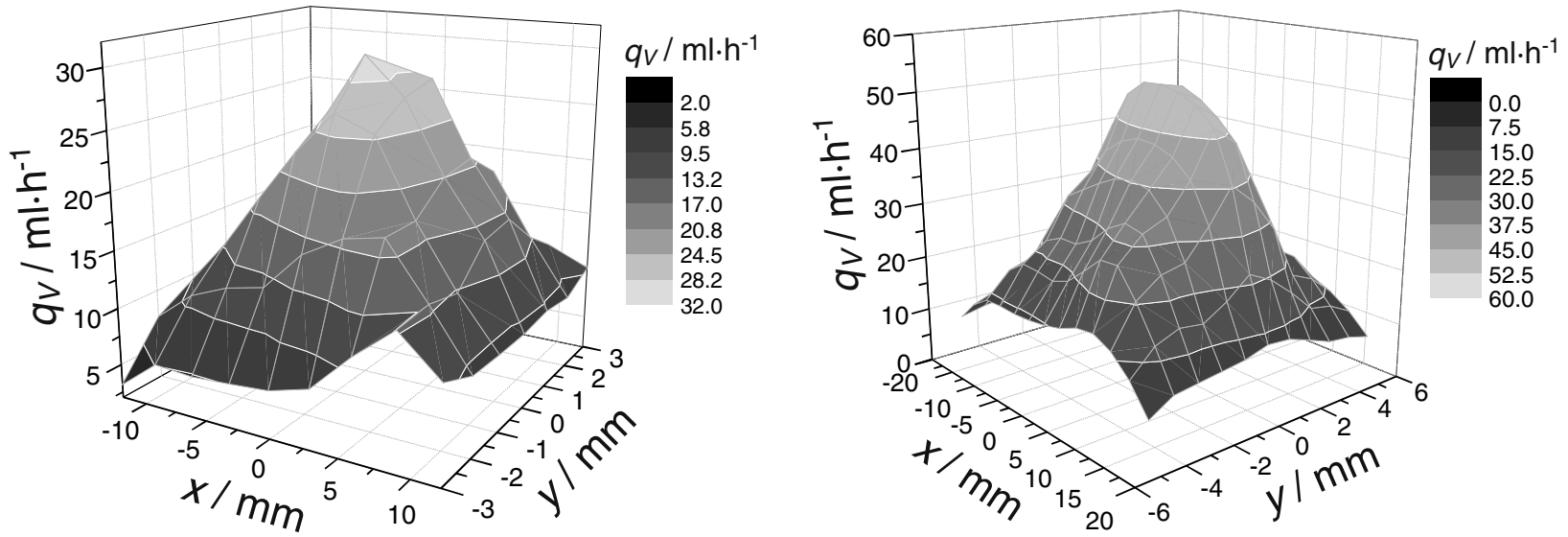

Fig. 11: Flow rates in the sensor capillary under a free impinging jet flow of a slit nozzle (see Fig. 4), flow rate of the nozzle: left diagram $1.5 \mathrm{I} \cdot \mathrm{min}^{-1}$; right diagram $3.4 \mathrm{I} \cdot \mathrm{min}^{-1}$ 

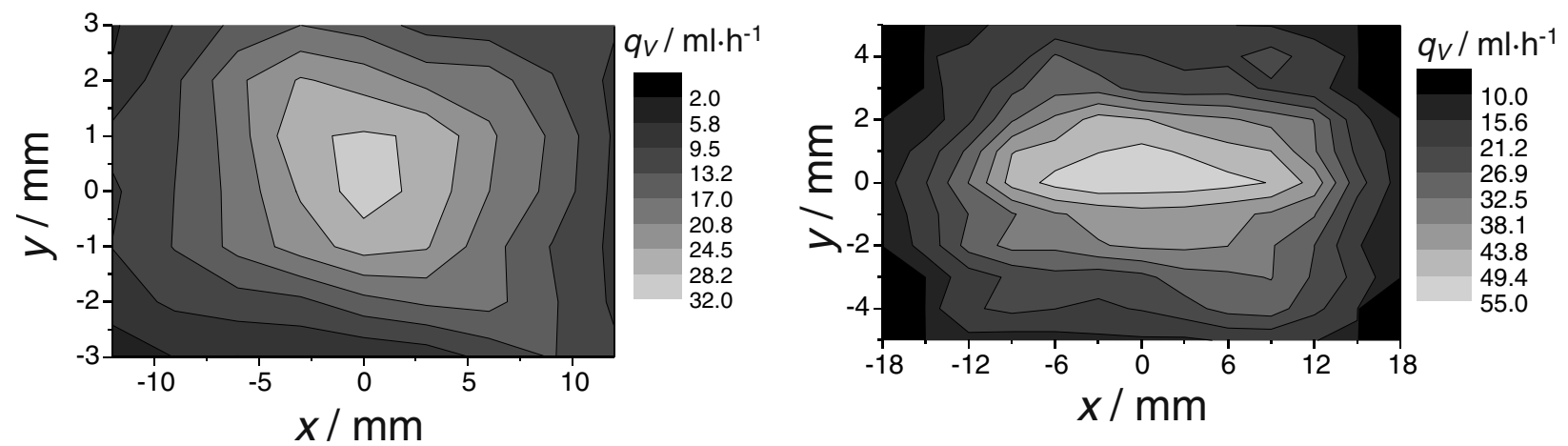

Fig. 12: Plan view on the cones given Fig. 11,

flow rate of the nozzle: left diagram $1.5 \mathrm{I} \cdot \mathrm{min}^{-1}$; right diagram $3.4 \mathrm{I} \cdot \mathrm{min}^{-1}$

The plan view on the cones of Fig. 11, which is given in Fig. 12, shows that the distribution of the flow rate is not symmetric and changes its shape significantly between the two flows. With these results and the estimation for minimum flow rates in through holes to be plated, published in [2], it is possible to proof the sufficiency of global nozzle arrangement and electrolyte outflow for optimal plating of micro structures.

\section{Conclusions}

A newly developed sensor with a fibre optical spatial filter is suited for flow measurement in micro capillary under the influence of free impinging jets. The sensor was tested successfully under laboratory conditions as well as in a galvanic line for horizontal plating of high density printed circuit boards. The available entrance length of the capillary $1 \mathrm{~mm}$ enables calibration-free measurement up to $50 \mathrm{ml} \cdot \mathrm{h}^{-1}$. At higher flow rates the values can be corrected by a second order polynomial.

The investigations of free impinging axisymmetric jets indicate that the capillary flow can be estimated by the pressure difference across the capillary, calculated by the empiric Equation given in [7] in case of turbulent jet and by $0.5 \rho u_{0}^{2}$ in case of laminar jets inside short jet lengths.

Tests in a section of a galvanic line for horizontal plating of high density printed circuit boards show that the sensor can be used reliably without recalibration or break of seal. The dosage of tracer particles is easy and disturbs neither the components nor the flow conditions in the plating line. Therefore, it is now possible for the first time to measure directly the influence of the flow conditions on the fluid exchange in microstructures in closed setups for surface modification.

\section{Literature}

[1] M. De Vogelaere, V. Sommer, H. Springborn, U. Michelsen-Mohammadein, High-speed plating for electronic applications, Electrochim. Acta, 47 (2001) 109-116.

[2] J. Zosel, U. Guth, A. Thies, B. Reents, Flow measurements in micro holes with electrochemical and optical methods, Electrochim. Acta, 48 (2003) 3299-3305.

[3] J. Zosel, W. Oelßner, U. Hauf, R. Ossiander, Elektrochemisches Sensorarray zur Messung konvektiver Prozesse in Mikrostrukturen, In: J.P. Baselt, G. Gerlach (Hg.): Dresdner Beiträge zur Sensorik, Band 20: 6. Dresdner Sensor-Symposium - Sensoren für zukünftige Hochtechnologien und Neuentwicklungen für die Verfahrenstechnik. Dresden: w.e.b. Universitätsverlag 2003, S. 67-70.

[4] D. Petrak, P. Mahr, Kalibrierung des faseroptischen Ortsfilter-Einpunkt-Durchflussgebers mittels Wägeverfahren, tm - Technisches Messen, 67 (2000) 474-478.

[5] F. Durst, S. Ray, B. Ünsal, O. A. Bayoumi, The development lengths of laminar pipe and channel flows, Journal of Fluids Engineering, 127, (2005) 1154-1160.

[6] S. Kenny, B. Reents, J. Zosel, Plating High Aspect Ratio PCBs, Printed Circuit Design \& Manufacture 22 (2005) 1, 22-29.

[7] G. Bollrich, Technische Hydromechanik, Bd.2, (1989) VEB Verlag für Bauwesen, Berlin, S. 276.

\section{Acknowledgement}

The support of the Arbeitsgemeinschaft industrieller Forschungsvereinigungen „Otto von Guerike“ e. V. (AiF) and of Deutsche Gesellschaft für Galvano- und Oberflächentechnik e.V. is gratefully acknowledged (support code $15070 \mathrm{BR} / 1$ and $15070 \mathrm{BR} / 2$ ). 